\title{
Comparison of Soybean Cultivars Enriching Cd and the Application Foreground of the Low-Accumulating Cultivar in Production
}

\author{
Siqi Wang ${ }^{1,2}$, Shuhe Wei ${ }^{1 *}$, Yanqiu Chen ${ }^{3}$, Mihajlov Ljupco $^{4}$ \\ ${ }^{1}$ Key Laboratory of Pollution Ecology and Environmental Engineering, Institute of Applied Ecology, \\ Chinese Academy of Sciences, Shenyang 110016, P.R. China \\ ${ }^{2}$ University of the Chinese Academy of Sciences, Beijing 100039, P.R. China \\ ${ }^{3}$ Crop Institute, Liaoning Academy of Agricultural Science, Shenyang, Liaoning 110161, P.R. China. \\ ${ }^{4}$ Faculty of Agriculture, Goce Delcev Univeristy, Stip 2000, Republic of Macedonia
}

Received: 7 October 2016

Accepted: 6 December 2016

\begin{abstract}
Contaminated soil collected from an agricultural field was used to compare Cd enrichment among 20 soybean cultivars to explore their application foregrounds in safe production. The results showed that $\mathrm{Cd}$ concentration in beans of 20 soybean cultivars was from $0.23 \mathrm{mg} \mathrm{kg}^{-1}$ to $2.33 \mathrm{mg} \mathrm{kg}^{-1}$ when Cd concentration in soil was $1.98 \mathrm{mg} \mathrm{kg}^{-1}$. Cd enrichment factors of 19 cultivars were lower than 1 . Cd translocation factors of all cultivars were lower than 1 . As for background soil with $0.15 \mathrm{mg} \mathrm{kg}^{-1} \mathrm{Cd}$, the concentrations of $\mathrm{Cd}$ in beans of two soybean cultivars were higher than $0.10 \mathrm{mg} \mathrm{kg}^{-1}$ (an agricultural trade standard of non-pollution food for soybean of China, NY5310-2005). Thus, the use of a low-accumulation soybean cultivar in Cd-contaminated soil should be done carefully and with reserve.
\end{abstract}

Keywords: Cd, soybean cultivar, enrichment factor, phytoremediation, safe production

\section{Introduction}

Research on Cd contamination of soybean in fields and health risk are scarce. Under field conditions, $\mathrm{Cd}$ concentration in soybean grain was found to be higher than that of corn in the experiment of comparing the $\mathrm{Cd}$ enrichment factor among wheat, rice, soybean, and corn when $\mathrm{Cd}$ concentration with $0.5 \mathrm{mg} \mathrm{kg}^{-1}$ or $1.5 \mathrm{mg} \mathrm{kg}^{-1}$

*e-mail: shuhewei@iae.ac.cn was added to soil [1]. In another field determination experiment, soybean $\mathrm{Cd}$ concentrations ranged from 1.08 to $1.71 \mathrm{mg} \mathrm{kg}^{-1}$ when soil Cd concentration was from 2.91 to $218 \mathrm{mg} \mathrm{kg}^{-1}$. The results indicated that grain $\mathrm{Cd}$ rice was equal to that in soybean [2]. Furthermore, the differences in cadmium uptake between plant species and cultivars of oat, wheat, soybean, beans, sunflower, cucumber, corn, leaf mustard, radish, cabbage, rape, sweet potato, carrot, and lettuce were compared using a nutrient solution experiment. They found that $\mathrm{Cd}$ concentration in beans was higher than that in food parts of oat and wheat [3]. Obviously, the enrichment of soybean to Cd was not very 
low. Cleaning Cd-contaminated soil is needed for the safe production of crops, especially for soybeans.

The washing method is usually very effective for heavy metal-polluted sites. But it is difficult to be used in agricultural fields with huge areas and middle or low contamination levels due to technological or economic reasons. Phytoextraction is a promising technology of phytoremediation, which mainly uses hyperaccumulator or accumulator to remove heavy metal from contaminated soil. Some famous hyperaccumulators have been widely studied, especially for $\mathrm{Zn}$ hyperaccumulator Thlaspi caerulescens [4], As hyperaccumulator Pteris vittata [5], $\mathrm{Zn}$ and Cd hyperaccumulator Sedum alfredii [6], and Cd hyperaccumulator Solanum nigrum L. [7]. However, too much research has focused on their hyperaccumulative mechanisms to heavy metals, and seldom was widely applied to remedy contaminated agricultural soil due to their lower removal rate and longer time [8-9]. Thus, another idea is to plant low-accumulation crops in heavy metal-contaminated soil to produce safe food [10]. As for some non-food plants, named with excluder plant was another method of phytoremediation, i.e. phytostabilization, to reduce ecological risk of wind and water erosion roles through their growth with very low concentrations of heavy metals in shoots [11].

Usually, there were four basic accumulation characteristics to judge a hyperaccumulator: 1) accumulation property, i.e., heavy metal concentration in stems or leaves must exceed the typical value; 2) translocation property, i.e., $\mathrm{TF}>1$ (translocation factor$\mathrm{TF}$, concentration ratio of shoots to roots); 3 ) enrichment property, i.e., EF $>1$ (enrichment factor-EF, concentration ratio of plant to media); and 4) tolerance property, i.e., biomass should not significantly decrease [12]. By contrast, the accumulation properties of low-accumulation crops are reversed to that of a hyperaccumulator, i.e., a) low accumulation with the lowest heavy metal concentration in food, b) $\mathrm{TF}<1, \mathrm{c}) \mathrm{EF}<1$, and d) strong tolerance without decreased biomass [10]. Though there are relative trade standards of non-polluted food, the low-accumulation property for a low-accumulation crop is relative due to the fact that heavy metal concentration in food may be low enough as to be undetectable. Thus, the cultivar with the lowest concentration of heavy metal in dozens of tested crop cultivars was regarded as a low-accumulation one [10]. In China, soybean is a very important crop alongside rice, corn, and wheat. This paper was focused on comparing $\mathrm{Cd}$ accumulation differences in beans of 20 soybean cultivars planted in Shenyang in northeastern China to find a low-accumulation cultivar and to explore its application foreground in polluted soil. It was hypothesized that some cultivars could show low accumulation characteristics to $\mathrm{Cd}$.

\section{Materials and Methods}

\section{Basic Properties of Polluted Soil Samples}

A Cd-polluted soil sample was collected from the top layer $(0-20 \mathrm{~cm})$ of an agricultural field in western suburb of Shenyang in northeastern China. The pollution was caused by wastewater irrigation from a large smelting plant. The soil was meadow brown with $\mathrm{pH}$ 6.7, and the concentration of $\mathrm{Cd}$ in the soil sample was $1.98 \mathrm{mg} \mathrm{Kg}^{-1}$. Compared to the Soil-Environmental Quality Standards of China classification (GB-15618-1995) and pollution status in the local district, the Cd pollution level was light-middle. Other basic physicochemical properties are shown in Table 1.

\section{Pot Culture Experiment}

We processed the pot culture experiment in a glasshouse $\left(41^{\circ} 31^{\prime} \mathrm{N}\right.$ and $\left.123^{\circ} 41^{\prime} \mathrm{E}\right)$ of the Institute of Applied Ecology of CAS in Shenyang. At this site, a plant can normally grow 127-164 days per year with average annual temperature about $5-9^{\circ} \mathrm{C}$ and annual precipitation of 650-700 $\mathrm{mm}$ [11].

Prior to the experiment, the soil sample and fertilizer such as $\left(\mathrm{NH}_{4}\right)_{2} \mathrm{SO}_{4}$ were thoroughly mixed to ensure uniformly homogenous distribution of $\mathrm{Cd}$. After sieving, the soil sample was transferred into plastic pots $20 \mathrm{~cm}$ in diameter and $18 \mathrm{~cm}$ in height, yielding a total dry weight of $2.5 \mathrm{Kg}$ of soil per pot. In the meantime, some clean soil collected from the other side of a polluted field was used as the control $(\mathrm{CK})$ with background concentration of $0.15 \mathrm{mg} \mathrm{kg}^{-1} \mathrm{Cd}$.

Seeds of 20 different soybean cultivars were bought from a local market at Shenyang and the detail names are shown in Table 2. All soybean seeds were sown in all pots as CK- and Cd-polluted soil at springtime. After the soybean seedlings were about $5 \mathrm{~cm}$ high, three uniform seedlings were kept in each pot.

Table 1. Basic physicochemical properties in the tested soil.

\begin{tabular}{|c|c|c|c|}
\hline Item & Soil sample & Item & Soil sample \\
\hline $\mathrm{pH}$ & 6.7 & Total-N $\left(\mathrm{g} \mathrm{kg}^{-1}\right)$ & 1.91 \\
\hline CEC $(\mathrm{cmol} \mathrm{kg})$ & 23.7 & Available-P $\left(\mathrm{mg} \mathrm{kg}^{-1}\right)$ & 16.42 \\
\hline Clay $(\%)$ & 18.9 & Available-K $\left(\mathrm{mg} \mathrm{kg}^{-1}\right)$ & 18.93 \\
\hline Silt $(\%)$ & 33.5 & TOC $\left(\mathrm{g} \mathrm{kg}^{-1}\right)$ & 1.98 \\
\hline Sand $(\%)$ & 47.6 & Total-Cd $\left(\mathrm{mg} \mathrm{kg}^{-1}\right)$ & \\
\hline
\end{tabular}


Table 2. Soybean cultivars used in the experiment.

\begin{tabular}{|c|c|c|c|c|c|c|c|}
\hline No. & Cultivar & No. & Cultivar & No. & Cultivar & No. & Cultivar \\
\hline S1 & Liaodou 13 & S6 & Liaodou 13 & S11 & Liaodou 34 & S16 & Liaohedou 4 \\
\hline S2 & Liaodou 14 & S7 & Liaodou 13 & S12 & Liaodou 35 & S17 & Liaohedou 6 \\
\hline S3 & Liaodou 16 & S8 & Liaodou 13 & S13 & Liaodou 36 & S18 & Liao00128 \\
\hline S4 & Liaodou 20 & S9 & Liaodou 13 & S14 & Tiefeng 33 & S19 & Liao04M05-3 \\
\hline S5 & Liaodou 22 & S10 & Liaodou 13 & S15 & Liaohedou 3 & S20 & Zhexian 5 \\
\hline
\end{tabular}

All pots with each treatment in triplicate were randomly placed in the net house. Using tap water to replenish the losses of water and maintain $80 \%$ soil waterholding capacity. All plants were and collected at maturity about 120 days after germination.

\section{Sample Determination and Data Processing}

About half of the plant samples were used to determine the shoot $\mathrm{Cd}$ concentrations. The other half of the plants were used to analyze $\mathrm{Cd}$ concentrations in roots, stems, leaves, pods, and beans. Tap water was used to rinse the plant samples, which were then carefully washed with deionized water. After being stored at $105^{\circ} \mathrm{C}$ for 5 minutes and then at $70^{\circ} \mathrm{C}$ for about 2 days, oven-dried plant samples were ground to powder and passed through a $0.3 \mathrm{~mm}$ sieve. Concentrated nitric acid and perchlorate at a ratio of $87 \% \mathrm{HNO}_{3} / 13 \% \mathrm{HClO}_{4}$ were used to digest soil and plant samples. Atomic absorption spectrophotometry (AAS, WFX-120A) with a $1.3 \mathrm{~nm}$ spectral bandwidth was used to determine the samples with higher $\mathrm{Cd}$ concentrations, especially in soil and leaves [8]. Moreover, an ICP mass spectrometer (NexION 300X) was used to analyze the samples with lower $\mathrm{Cd}$ concentrations, especially for beans, so that the valuable data can be more precise and the value of a lower $\mathrm{Cd}$-accumulating cultivar may come down to the food safety limit. As for QA/QC, certified standard reference materials (NIST SRM 1547, peach leaves) were used to measure values of $\mathrm{Cd}$ (Zhan et al., 2013). A pH meter (PHS-3B) was used to determine soil $\mathrm{pH}$ (soil: water ratio as $1: 2.5$ ). Normal methods that were used quite often and introduced by $\mathrm{Lu}$ et al. were

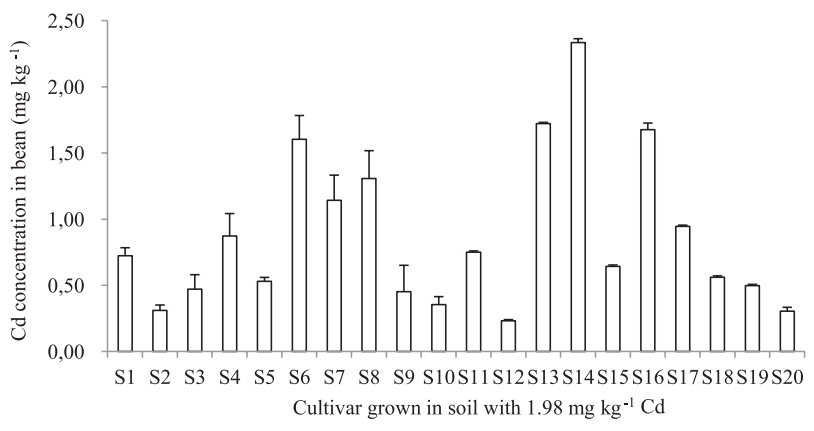

Fig. 1. Cd concentrations in beans of different soybean cultivars grown in polluted soil. conducted to analyze such basic soil properties as CEC, clay, silt, sand, total-N, available-P, and TOC [10].

Data processing and calculations of standard errors (SD) were carried out using Microsoft EXCEL. The differences of $\mathrm{Cd}$ concentrations in beans of different soybean cultivars grown in polluted soil were analyzed using the cluster analysis test to separate means using SPSS software.

\section{Results and Discussion}

\section{Differences of Cd Concentrations in Beans Among Different Soybean Cultivars}

Fig. 1 showed Cd concentrations in beans of 20 soybean cultivars. Obviously, the differences of Cd concentrations in beans were huge when they grew in polluted soil with $1.98 \mathrm{mg} \mathrm{kg}^{-1} \mathrm{Cd}$. It was thought that their different gene bases may play an important role [13].

In order to compare the differences between any two cultivars, cluster analysis was used to separate means of $\mathrm{Cd}$ concentration in beans. As shown in the dendrogram of Fig. 2, the cultivar with the highest $\mathrm{Cd}$ concentration in beans was Tiefeng $33\left(2.33 \mathrm{mg} \mathrm{kg}^{-1}\right)$ and the lowest was Liaodou $35\left(0.23 \mathrm{mg} \mathrm{kg}^{-1}\right)$. The difference of between

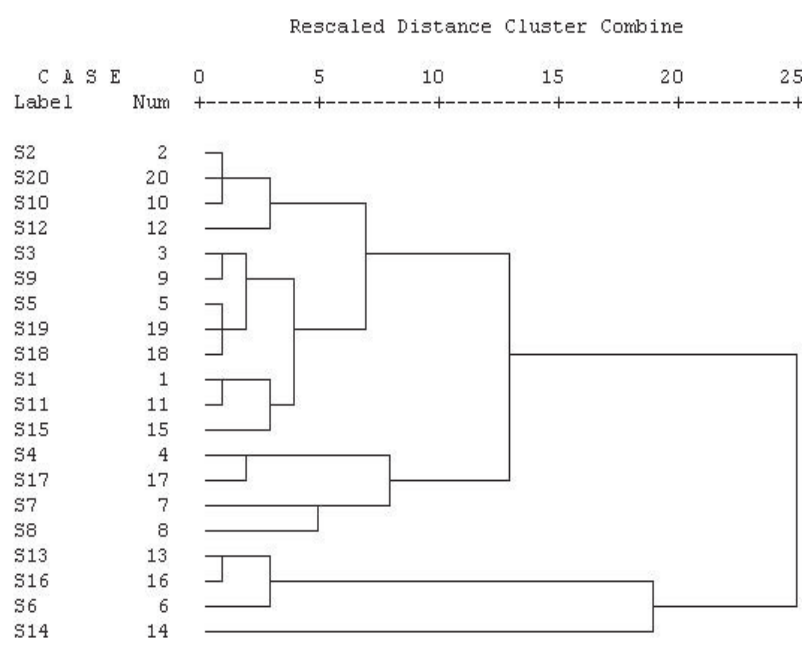

Fig. 2. Dendrogram of cluster analysis test among soybean cultivars based on $\mathrm{Cd}$ concentration in beans. 
the highest and the lowest was about 10 times and the average of the 20 cultivars was $0.87 \mathrm{mg} \mathrm{kg}^{-1}$. However, all $\mathrm{Cd}$ concentrations in beans were higher than $0.10 \mathrm{mg} \mathrm{kg}^{-1}$, an agricultural trade standard of nonpollution food for soybeans of China (NY5310-2005), indicating that the low accumulation soybean cultivar was unavailable to safely produce food when Cd concentration in soil was higher than $1.98 \mathrm{mg} \mathrm{kg}^{-1}$. Compared to other soybean cultivars, Liaodou 35 was relatively low accumulation based on Cluster analysis (Fig. 2).

\section{Differences of Enrichment and Translocation Factors}

Enrichment factor (EF), i.e., the rate of heavy metal concentration in plant shoot to soil, indicates the potential of a plant to accumulate heavy metals. Lower EF (i.e., $\mathrm{EF}<1$ ) should be an important property for low accumulation crops [10]. The EF differences of 20 soybean cultivars were very large with the highest and lowest values were 1.47 (Tiefeng 33) and 0.14 (Liaodou $35)$, respectively, with an average of 0.46 . The former was about 10 the latter (Fig. 3a). Except for Tiefeng 33, other EFs of soybean cultivars were all lower than 1 . In contrast, Tiefeng 33 showed a higher accumulation potential and Liaodou 35 indicated lower property.

Translocation factor (TF) is another important index expressing the translocation capacity of a plant to heavy metal from root to shoot, i.e., the rate of concentration in shoots to roots. Thus, lower $\mathrm{TF}$ (i.e., $\mathrm{TF}<1$ ) also should be necessary for low-accumulation crops [10]. As shown in Fig. 3b, all TFs of 20 soybean cultivars were lower than 1 and the average was 0.40 . The highest was Tiefeng 33 with 0.79 and the lowest was Liao00128 with 0.15 . The TF of Liaodou 35 also was low, at 0.20.

Based on Cd concentration in beans, EFs and TFs of 20 soybean cultivars, Tiefeng 33 was a high-accumulation cultivar and Liaodou 35 was a low-accumulation one by contrast (Figs 1-3).

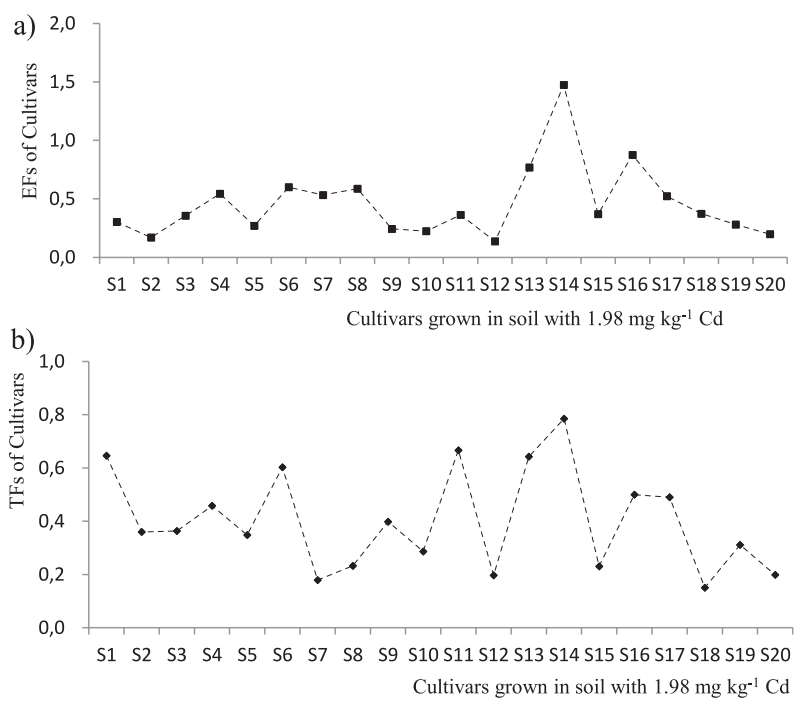

Fig. 3. EF and TF of tested soybean cultivars to $\mathrm{Cd}$.

\section{Application Foreground of Low Accumulation} Soybean cultivar

The Soil-Environmental Quality Standards of China classification (GB-15618-1995) specified that $\mathrm{Cd}$ concentration in soil was background level at less than $0.2 \mathrm{mg} \mathrm{kg}^{-1}$ (first class), and $0.3 \mathrm{mg} \mathrm{kg}^{-1}$ and $1.0 \mathrm{mg} \mathrm{kg}-1$ were the second and third classes when $\mathrm{pH}$ is 6.5-7.5, or higher than 6.5. Usually, soil is considered to be contaminated by $\mathrm{Cd}$ when its concentration in soil is higher than the second or third class (GB-15618-1995).

Fig. 4 shows Cd background concentration in beans of 20 different soybean cultivars when $\mathrm{Cd}$ concentration in soil was $0.15 \mathrm{mg} \mathrm{kg}^{-1}$. The concentrations of $\mathrm{Cd}$ in beans were from $0.02 \mathrm{mg} \mathrm{kg}^{-1}$ to $0.13 \mathrm{mg} \mathrm{kg}^{-1}$ with an average of $0.07 \mathrm{mg} \mathrm{kg}^{-1}$. The $\mathrm{Cd}$ concentration of low accumulation cultivar of Liaodou 35 was $0.02 \mathrm{mg} \mathrm{kg}^{-1}$. However, Cd concentration in beans of Liaodou $23\left(0.13 \mathrm{mg} \mathrm{kg}^{-1}\right)$ and Tiefeng $33\left(0.11 \mathrm{mg} \mathrm{kg}^{-1}\right)$ were higher than the value of $0.10 \mathrm{mg} \mathrm{kg}^{-1}$ of the agricultural trade standard of nonpollution food for soybeans of China (NY5310-2005). Obviously, Cd concentration in beans may be higher than the standard $\left(0.10 \mathrm{mg} \mathrm{kg}^{-1}\right)$, and even some soybean cultivars grow in clean soil only with background levels. Roughly calculated by the average EF of the ratio of $\mathrm{Cd}$ concentration in beans to that of in soil with as $0.44, \mathrm{Cd}$ concentration in beans may exceed the standard $0.1 \mathrm{mg} \mathrm{kg} \mathrm{kg}^{-1}(0.44 \times 0.3=0.13 \mathrm{mg} \mathrm{kg}-1)$ when $\mathrm{Cd}$ concentration in soil was higher than the second class $\left(0.3 \mathrm{mg} \mathrm{kg}^{-1}\right)$. Thus, the foreground of soybean cultivars even for low accumulation ones used to produce beans with $\mathrm{Cd}$ concentrations lower than $0.10 \mathrm{mg} \mathrm{kg}^{-1}$ in Cd-contaminated soil may not be promising. The production of soybeans in Cd-contaminated soil should be done carefully and with reserve.

Recently, research about low-accumulation crops was becoming a hot topic in environmental science. Greger and Lofstedt compared the uptake and distribution of cadmium in different cultivars of bread and durum wheat. It was found that the differences among wheat cultivars accumulating $\mathrm{Cd}$ in grains was very big based on an experiment using a nutrient solution containing $0.5 \mathrm{mM}$ $\mathrm{Cd}$ in a climate chamber. The reason may be caused by

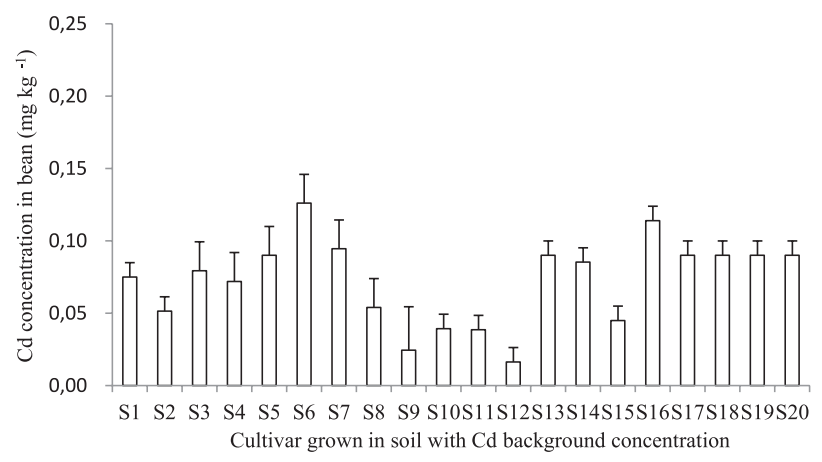

Fig. 4. Cd background concentrations in beans of different soybean cultivars. 
the translocation capacities from roots to shoots [14]. Yu and Zhan et al. confirmed the importance and feasibility of screening rice cultivars for pollution-safe production from 43 cultivars of paddy rice (Oryza sativa L., including 20 normal and 23 hybrid cultivars) under a high (75.69$77.55 \mathrm{mg} \mathrm{kg}^{-1}$ ) and low (1.75-1.85 $\left.\mathrm{mg} \mathrm{kg}^{-1}\right) \mathrm{Cd}$ soil in pots [15]. However, studies concerning soybeans were scarce.

Using a greenhouse study, the accumulation safety for food of soybean (Glycine max (L.) Merr.) to Cd was assessed [16]. The results showed that too much $\mathrm{Cd}$ was kept in roots. A little $\mathrm{Cd}$ was translocated to pods and seeds. But the seeds of all plants, including the control, had concentrations of Cd 3-4 times above the limit of $0.2 \mathrm{mg} \mathrm{kg}^{-1}$ as set by the Codex Alimentarius Commisson. Thus, it was suggested that monitoring concentrations of toxic metals in food crops was needed given that $\mathrm{Cd}$ in the soil was well below the maximum allowable amount for agricultural soil [16]. By using soil (four soil types, containing from 0.2 to $6.5 \mathrm{mg} \mathrm{kg}^{-1}$ extractable Cd) first and then nutrient solution (containing $100 \mu \mathrm{g} \mathrm{L}^{-1} \mathrm{Cd}$ ), Arao et al. explored the $\mathrm{Cd}$ enrichment difference mechanisms among 17 varieties of soybeans [17]. Basically, the differences in uptake and distribution of $\mathrm{Cd}$ in different soybean cultivars were huge, and "significant genotypic differences in seed $\mathrm{Cd}$ levels were found," indicating that there was a relative variety of genotypes [17]. In northeastern China, 23 Chinese soybean varieties (different from the soybean cultivars tested in this paper) were assessed for $\mathrm{Pb}$ and $\mathrm{Cd}$ tolerance and accumulation potential [18-19]. Based on the Cd threshold of $0.2 \mathrm{mg} \mathrm{kg}^{-1}$ in foods of peas and beans (National food safety standards, China, GB2762-2012, issued by the Ministry of Health of China), only one low-accumulation Cd soybean cultivar was suggested [19]. In the present article, $\mathrm{Cd}$ concentration with $0.10 \mathrm{mg} \mathrm{kg}^{-1}$ in beans (seeds) based on an agricultural trade standard of nonpollution food for soybean of China (NY5310-2005) was regarded as the standard of low accumulation soybeans. This standard was thought to be better due to considering the remediation and safe use of polluted agricultural soil. The Cd threshold of $0.2 \mathrm{mg} \mathrm{kg}^{-1}$ in foods of peas and beans is too wide. Furthermore, it was suggested that $\mathrm{Cd}$ concentration in seeds (beans) may be hazardous to human health - even some soybean cultivars grown on soils with permitted levels, which was identical to the present paper [19]. Thus, low-accumulation soybean cultivars should be carefully and reservedly used in Cd-contaminated soil.

\section{Conclusions}

Screening low-accumulation soybean cultivars is very important, although not too many studies have been published. The accumulation difference in 20 soybean cultivars to $\mathrm{Cd}$ was determined in the present experiment. A huge $\mathrm{Cd}$ accumulation difference was found among different varieties of soybeans. In contrast, $\mathrm{Cd}$ concentration in the seeds of one cultivar was very low. However, the application of low Cd accumulations in soybean cultivar with a careful and reserved idea also has been suggested.

\section{Acknowledgements}

This work was supported by the National Key Research and Development Program of China in the $13^{\text {rd }}$ Five-Year Plan (2016YFD0800802), the General Program of National Natural Science Foundation of China (41571300, 31270540, and 31070455), Hi-tech research and development program of China (2012AA06A202) and the Sino-Macedonia Government Scientific and Technology Cooperation Project (3-2).

\section{References}

1. WANG X., WU Y.Y. The accumulation characteristics of different crops to combined heavy metals. Agro-Environ Protection. 17, 193, 1998.

2. SIMMONS R.W., PONGSAKUL P., CHANEY R.L., SAIYASITPANICH D.S., KLINPHOKLAP S., NOBUNTON W. The relative exclusion of zinc and iron from rice grain in relation to rice grain cadmium as compared to soybean: Implications for human health. Plant Soil. 257, $163,2003$.

3. PETERSON O. Differences in cadmium uptake between plant species and cultivars. Swedish J Agri Sci. 7, 21, 1977.

4. AAD S., YOUNG S., WEST H. Effect of nickel and cadmium on glucosinolate production in Thlaspi caerulescens. Pakistan J Botany. 45, 495, 2013.

5. WAN X.M., LEI M., CHEN T.B., YANG J.X., LIU H.T., CHEN Y. Role of transpiration in arsenic accumulation of hyperaccumulator Pteris vittata L. Environ Sci Pollut Res. 22, 16631, 2015.

6. CHEN B., MA X.X., LIU G.Q., XU X.M., PAN F.S., ZHANG J., TIAN S.K., FENG Y., YANG X.E. An endophytic bacterium Acinetobacter calcoaceticus Sasm3enhanced phytoremediation of nitrate-cadmium compound polluted soil by intercropping Sedum alfredii with oilseed rape. Environ Sci Pollut Res. 22, 17625, 2015.

7. WEI S.H., BAI J.Y., YANG C.J., ZHANG Q.R., KNORR K., ZHAN J., GAO Q.H. Compound amino acids added in media improved Solanum nigrum L. phytoremediating CdPAHs contaminated soil. Inter J Phytoremediation. 18, 358, 2016.

8. ENRICA R., HELENA CRISTINA S., MAURO GIORGIO M., CRISTINA B. The impact of Ni on the physiology of a Mediterranean Ni-hyperaccumulating plant. Environ Sci Pollut Res. 23, 12414, 2016.

9. PAULA C., ZYGMUNT MARIUSZ G., IGOR C. Phytoextraction of $\mathrm{Cd}$ and $\mathrm{Zn}$ as single or mixed pollutants from soil by rape (Brassica napus). Environ Sci Pollut Res. 23, 10693, 2016.

10. LIU W.T., ZHOU Q.X., AN J., SUN Y.B., LIU R. Variations in cadmium accumulation among Chinese cabbage cultivars and screening for Cd-safe cultivars. J Hazard Mater. 173, 737, 2010.

11. ZHAN J., WEI S.H., NIU R.C., LI Y.M., WANG S.S., ZHU J.G. Identification of rice cultivar with exclusive characteristic to $\mathrm{Cd}$ using a field-polluted soil and its 
foreground application. Environ Sci Pollut Res. 20, 2645, 2013.

12. WEI S.H., ANDERS I., FELLER U. Selective uptake, distribution and redistribution of ${ }^{109} \mathrm{Cd},{ }^{57} \mathrm{Co},{ }^{65} \mathrm{Zn},{ }^{63} \mathrm{Ni}$ and ${ }^{134} \mathrm{Cs}$ via xylem and phloem in the heavy metal hyperaccumulator Solanum nigrum L. Environ Sci Pollut Res. 21, 7624, 2014.

13. GRANT C.A., CLARKE J.M., DUGUID S., CHANEY R.L. Selection and breeding of plant cultivars to minimize cadmium accumulation. Sci Total Environ. 390, 301, 2008.

14. GREGER M., LOFSTEDT M. Comparison of uptake and distribution of cadmium in different cultivars of bread and durum wheat. Crop Sci. 44, 501, 2004.

15. YU H., WANG J.L., FANG W., YUAN J.G., YANG Z.Y. Cadmium accumulation in different rice cultivars and screening for pollution-safe cultivars of rice. Sci Total Environ. 370, 302, 2006.

16. SHUTE T., MACFIE S.M. Cadmium and zinc accumulation in soybean: A threat to food safety? Sci Total Environ. 37, 63, 2006.

17. ARAO T., AE N., SUGIYAMA M., TAKAHASHI M. Genotypic differences in cadmium uptake and distribution in soybeans. Plant Soil. 251, 247, 2003.

18. ZHI Y., SUN T., ZHOU Q.X. Assessment of lead tolerance in 23 Chinese soybean cultivars and the effect of lead on their mineral ion complement. Environ Sci Pollut Res. 21, 12909, 2014.

19. ZHI Y., SUN T., ZHOU Q.X., ZHU Y.Q. Assessment of potential soybean cadmium excluder cultivars at different concentrations of Cd in soils. J Environ Sci. 35, 108, 2015. 